\title{
A groupwork approach to focus group research in the context of a psychiatric clubhouse program
}

\author{
W. J. Casstevens ${ }^{1}$ and Marcia B. Cohen ${ }^{2}$
}

\begin{abstract}
This article explores the use of focus groups with a vulnerable client population to facilitate the development of non-profit agency programming. A series of four focus groups on health and wellness at a psychiatric Clubhouse was recorded and transcribed. Transcription analysis indicated the group facilitator reached for feelings, encouraged sharing, and was consistently empathic. These and other departures from the data gathering role are examples of Cohen and Garrett's (1999) recommendations on integrating groupwork skills and focus group research, all of which supported meaningful sharing and brain-storming that enhanced the development of health and wellness programming at the Clubhouse.
\end{abstract}

Keywords: focus groups; clubhouse programs; health; groupwork

1. Dept of Social Work, North Carolina State University

2. School of Social Work, University of New England, Portland Maine

Address for correspondence: Dept of Social Work, North Carolina State University, Campus Box 7639, Raleigh, NC 27695-7639,USA.wjcasste@ncsu.edu

Acknowledgement: The authors would like to thank Health and Wellness Program Developer J. M. Spellmeyer, MS, MSW, and Transcriptionist D. M. Kim, BSW student, for their work on this project, as well as the North Carolina State University Office of Extension, Engagement and Economic Development for the funding that made the project possible. An earlier draft of this paper was presented at the $32^{\text {nd }}$ Association for Advancement of Social Work with Groups International Symposium in Montreal, Canada (2010). 
A group work approach to focus group research in a psychiatric clubhouse program

\section{Introduction}

Psychiatric Clubhouses are psycho-social rehabilitation programs that offer adults who have been given a psychiatric diagnosis membership of a community which emphasizes productive activity and a work-ordered day. The Clubhouse model began with Fountain House in New York City which opened in 1948 as the first of its kind. The model's spread in the late 1970s and early 1980s coincided with deinstitutionalization and the need of former State hospital patients for meaningful daily activity in a safe community venue. Clubhouse programs are now found around the globe, and the International Center for Clubhouse Development certifies programs that follow this rehabilitative model (International Center for Clubhouse Development, www.iccd.org). Health and wellness are a particular concern for the population Clubhouses serve (Hutchinson et al, 2006; Pelletier et al, 2005), and focus groups have been used to develop viable and self-sustaining health and wellness initiatives in this organizational venue (Casstevens, 2010). This study examines the process of a series of recorded focus groups on health and wellness in order to identify non-standard facilitator interventions: The interventions were used to engage focus group participants, in order to collect background information and stimulate creative ideas about health and wellness program development at a psychiatric Clubhouse in a city in the southern United States of America.

Focus groups have been used extensively in health related areas to explore a variety of topics, and have been used in social science research for over 80 years (Redmond and Curtis, 2009). In health related research, focus groups have been used to gain entry into difficult to access communities (e.g., Smith et al, 2002), with culturally diverse populations (e.g., Napolitano et al, 2002), and to explore sensitive areas (e.g., Jones et al, 2009; Tolliver, 2001). Such research has addressed, for example, care-giving (Kramer and Auer, 2005; Tolliver, 2001), physical activity and/or nutrition (Bauer et al, 2004; Patacca et al, 2004; Young et al, 2001); and childhood obesity (Jones et al., 2009).

Since focus groups are information gathering tools, it is perhaps not surprising that much has been written on information gathered by and/or developed based upon focus groups; work has also been done, however, on ways to successfully conduct focus groups, and on the group process itself (e.g., Loeb et al, 2006; Napolitano, et al., 
2002; Smith, et al., 2002). Redmond and Curtis (2009) have identified responsiveness and both reflective and non-reflective listening skills as characteristic of a good focus group facilitator. Cohen and Garrett (1999) went further in the context of mental health, taking a client-centered and strengths oriented approach to focus groups in recommending that social work researchers revise and refine focus group research based on groupwork principles including sensitivity to focus group participants' psycho-social needs.

While Clubhouse model programs serve mental health service users, Clubhouses avoid clinical treatment approaches and groupwork. Instead, they offer structured opportunities for meaningful daily activity, as well as supported and transitional employment opportunities in the community for those who are interested. Clubhouse clients are called 'members,' but psychiatric Clubhouses are not social clubs; they may, however, offer an evening or weekend social program component, and may also offer a supported housing option. International Center for Clubhouse Development certification reflects that a Clubhouse implements ICCD standards (www.iccd.org), thereby adhering to a Clubhouse psycho-social rehabilitation model of programming.

This study analyzed a series of focus groups at a Clubhouse certified as an International Center for Clubhouse Development with Cohen and Garrett's (1999) groupwork oriented recommendations for focus group facilitation in mind. The focus groups utilized Glasser's (1998, 2000) choice theory, and Wubbolding's (2000) model for implementing choice theory in reality therapy, to explore health and wellness at the Clubhouse. The goal was to develop ways that the Clubhouse might support health and wellness for its membership. It was hoped that the focus groups would provide a venue in which collaborative consultation could occur.

Glasser's (1998) concept of Total Behavior is central to choice theory. All behavior, that is Total Behavior, has four parts, acting, thinking, feeling, and how the body reacts - that is, physiology. According to choice theory, all Total Behavior on one level or another is chosen, although most individuals only have direct control over acting and thinking. Further, individuals can control their feeling and physiology through how they choose to act and think. Thus based on choice theory, for Clubhouse health and wellness components to be successful, members need to actively engage and participate in them; further, 
members are more likely to do this if they develop the ideas from which these components spring, and perceive themselves as having personal choices involved with both the development of, and participation in, the health and wellness components (Casstevens, forthcoming). The focus group series provided a venue that allowed these processes to develop and was implemented at four Clubhouses in the area (Casstevens, 2010). Members of one Clubhouse consented to the audio-recording of their focus groups. The transcriptions from this focus group series provided the basis for this article.

Transcriptions were analyzed in order to explore the ramifications of any identified facilitator departures from the data-gathering role on participant issues, feelings and needs, and overall goal attainment. Because of the group series' theoretical basis in choice theory and reality therapy, it was anticipated that facilitator departures from the data-gathering role would focus on relationship building between and among participants, and that this was likely to incorporate many of Cohen and Garrett's client-centered and strengths oriented recommendations. Further, it was anticipated that the cumulative impact of such role departures would support Cohen and Garrett's overarching recommendation regarding the need to be sensitive and attend to focus group participants' psycho-social needs.

Cohen and Garrett's (1999) article, 'Breaking the rules: A groupwork perspective on focus group research,' looked at the implications of bringing a groupwork perspective and skills to focus group facilitation. Cohen and Garrett found that the original guidelines (essentially rules) for leading focus groups came from a business rather than a social science base and did not reflect what social workers as groupworkers know about group dynamics and group facilitation. That is, original focus group guidelines contradicted groupwork wisdom, stating that focus groups should: (a) be composed of people who do not know each other; (b) take place in neutral rather than natural settings; and (c) emphasize the information the researcher wishes to obtain, rather than be driven by the needs and socio-emotional concerns of group members. In actuality, of course, focus groups in social science research often consist of people who know one another and/or take place in natural settings; they are not, however, driven by the needs or socioemotional concerns of group members (Loeb et al, 2006; Redmond \& Curtis, 2009). 
Pursuant to this, Cohen and Garrett (1999) noted that focus group guidelines caution focus group leaders to avoid sensitive topics unless they directly pertain to focus group questions, and to maintain a detached and non-responsive, impersonal stance throughout the focus group session. Cohen and Garrett (1999), in contrast, advocated bringing groupwork wisdom and skills to focus group facilitation, which included: (a) being empathic, (b) reaching for feelings, (c) being personal and responsive, (d) being sensitive to the needs of group members and the group, and (e) building on the relationships and commonalities among members. They found that the effectiveness of focus groups can be enhanced when groupwork and research skills are integrated and the researcher and research subjects' needs are not dichotomized. Knowledge of group development and dynamics coupled with the skills of clarifying purpose, tuning in, focusing, and maintaining simultaneous focus on the individual and the group, constitute potent tools for effective focus group research. Cohen and Garrett (1999) concluded that by integrating groupwork knowledge with research knowledge, focus group research protocols can be modified and refined in a responsible fashion, in order to prove a better fit with the values and goals of social work research. Finally, they suggested social worker researchers, rather than merely breaking the rules of focus group research, take the lead in revising these rules or guidelines to be more sensitive to the socio-emotional needs of research subjects. Casstevens (2010) conducted a series of focus groups in mental health Clubhouse settings in North Carolina that did just what Cohen and Garrett (1999) advocated. The focus group facilitator, a licensed clinical social worker with extensive experience in groupwork, brought groupwork wisdom and skills to the focus groups conducted, with very good results.

\section{Background}

Focus groups began at the Clubhouse after the facilitator met with the Clubhouse's executive director, staff and members in order to explain the context and overall goal of the project. At that time, this Health and Wellness program development project was already in place at three other Clubhouses in central North Carolina. The program development 
A group work approach to focus group research in a psychiatric clubhouse program

project was approved by the first author's university Institutional Review Board for use of human subjects in research. Consultation with the director, staff and members at the fourth Clubhouse determined that there was interest in the proposed focus group series, even though the Clubhouse was unique among project sites in that it was already two years into another grant funded health and wellness initiative of its own.

Many of the health and wellness components program developers had facilitated at the three other Clubhouses were already established at this site. These included: regular walking groups, nutritionist visits, healthy menus in kitchen and at the snack bar, a smoking cessation program for those interested, and cooperative links with local yoga and YMCA facilities and health and wellness educational speakers. This Clubhouse also already offered weekly weigh-ins for weight reduction goals. Nevertheless, it was decided to go forward with the proposed focus group series to see what the members' views of health and wellness at the Clubhouse were and what they suggested as areas for further health and wellness development.

\section{Methods}

The four focus groups were recorded each week for subsequent transcription. A note-taker was present during groups, in the event a problem arose with the recording equipment, and/or recordings were unintelligible. The note-taker was the program developer assigned to the Clubhouse. Sign language interactions between deaf participants who attended the latter three groups were not recorded. One of these participants had partial hearing and read lips, then translated for another participant. After the second group, the facilitator was asked to summarize and repeat input from other participants at intervals, and the partially deaf participant sat so that the facilitator's face was visible. Prior to the focus groups, participants were not acquainted with the group facilitator or note-taker, though they knew one another at least by sight as fellow Clubhouse members; group process made it clear that participants ranged from friends of long-standing to individuals relatively unacquainted with one another. The Clubhouse did not offer groups as treatment interventions, and it is unclear whether participants were involved in or familiar with any type of groupwork before attending 
the focus groups at the Clubhouse.

The initial focus group consisted of six members, the facilitator, and the note-taker. A Clubhouse staff person selected the members to participate in the group that morning, and 6-8 participants were invited. It was, as the note-taker later remarked, a 'difficult' group process. In part this was because Focus Group I questions focused on individual views of participants' health, and all participants considered themselves basically healthy (something not encountered at the three previous Clubhouses). Also, towards the end of the group it became apparent that participants attended with the expectation that material/ information on health and wellness was to be conveyed to them. After recognizing this misunderstanding, the facilitator addressed it directly.

For Focus Group II the following week, the facilitator personally went to work areas at the clubhouse to invite staff and members to attend, and to clarify the purpose of the focus group. The number of participants was increased to 12 , because (based on the previous week's group process) it was recognized that Clubhouse members might choose to attend and observe without contributing verbally.

For Focus Group III, the same process was followed. After this group started, however, approximately six additional members came into the open group area, and pulled up chairs (the number is approximate, as several came and went during the group). This contributed to a more lively process, and sidebar discussions took place despite facilitator efforts to include such discussions into the main group process. This spontaneous increase in participation may have been due to the facilitator and program developer now being recognized and welcomed visitors to the Clubhouse.

The increased participation continued during the fourth and final focus group the following week, because there was no feasible way to limit group attendance. The space used was the only space available at the Clubhouse and was open on two sides, with the main entranceway adjacent to the space and open to it. At best, asking late-comers to leave would have required explanation that would have disrupted the ongoing group process. At worst, participants could have construed this as rejecting and/or rude, which in turn might have led to rejection of the facilitator and the group itself - participating members might have chosen to leave with friends or become silent. It was noted that sidebar conversations, when they arose, were not intentionally disruptive. 
During Focus Groups III and IV, therefore, additional participants drifted in and out at odd intervals, sometimes joining friends who were already present and participating.

Focus group dialog was recorded and transcribed in order to assess responses to role departures by examining positive and negative outcomes related to the overall goal of Health and Wellness program development. However, the increased and shifting attendance during Focus Groups III and IV made transcription difficult. In order to transcribe dialog, the transcriptionist used the written notes taken on a laptop during the group, and listened to two recordings made at either end of the table around which participants sat.

Initial review of the transcriptions by a non-participant confirmed that the facilitator followed Cohen and Garrett's (1999) recommendations. Subsequent transcription analysis specifically identified departures from the data-gathering focus group facilitator role. This content analysis of the transcribed dialog occurred in three stages:

1. a non-participant reviewer reviewed transcriptions and highlighted facilitator departures from the data-gathering role, identifying the categories of role-departures observed;

2. another reviewer, present during the focus groups, independently reviewed transcriptions and highlighted departures from the datagathering role; and

3. transcriptions were examined a second time by both reviewers to confirm the categories and number of role departures present in each focus group transcription (see Table 1). This transcription analysis was accomplished without the aid of any software program; results are discussed below. 
W. J. Casstevens and Marcia B. Cohen

Table 1. Categories of Role Departures Present in the Focus Groups

\begin{tabular}{|c|c|c|c|c|}
\hline \multirow[b]{2}{*}{ Role Departure } & \multicolumn{4}{|c|}{ Focus Group } \\
\hline & I & II & III & IV \\
\hline $\begin{array}{l}\text { Reaching for } \\
\text { thoughts/feelings }\end{array}$ & & $\mathrm{X}$ & $\mathrm{X}$ & \\
\hline $\begin{array}{l}\text { Eliciting participants' } \\
\text { responses to one another }\end{array}$ & & $\mathrm{X}$ & $\mathrm{X}$ & $\mathrm{X}$ \\
\hline Pointing out commonalities & $\mathrm{X}$ & $\mathrm{X}$ & $\mathrm{X}$ & $\mathrm{X}$ \\
\hline Empathizing & $\mathrm{X}$ & & $\mathrm{X}$ & \\
\hline Sharing personal information & $\mathrm{X}$ & & $\mathrm{X}$ & $\mathrm{X}$ \\
\hline $\begin{array}{l}\text { Reaching for socio- } \\
\text { emotional content }\end{array}$ & $\mathrm{X}$ & & $\mathrm{X}$ & $\mathrm{X}$ \\
\hline $\begin{array}{l}\text { Offering praise, } \\
\text { emphasizing strengths }\end{array}$ & & $\mathrm{X}$ & & $\mathrm{X}$ \\
\hline
\end{tabular}

\section{Results}

The initial review of the transcriptions identified that the facilitator: (1) reached for feelings, (2) reached for group members' responses to each other, (3) encouraged sharing, (4) was empathic, and (5) shared some personal information. It was also clear that the note-taker/ program developer was viewed as an important part of the group by the participants. Further, some of the group participants expressed during the process how much they enjoyed participating in the group. In sum, as noted above, initial review indicated that these groups were an excellent example of Cohen and Garrett's (1999) recommendations for researchers facilitating focus groups.

The categories of role departures present in the focus groups were identified as: (a) reaching for thoughts and feelings; (b) eliciting participants' responses to one another; (c) pointing out commonalities between and among participants; (d) empathizing; (e) sharing personal information; (f) reaching for socio-emotional content; and (g) offering praise, emphasizing strengths. As Table 1 Categories of Role Departures Present in the Focus Groups shows, the facilitator used responses that 
A group work approach to focus group research in a psychiatric clubhouse program

fell in four to six of the identified categories during each focus group. Only one response category was present in all four groups, that of pointing out commonalities.

The facilitator pointed out commonalities directly, for example, 'It sounds like in a way, there are some similar experiences here...' (Focus Group I). Eliciting participants' responses to one another, one of three categories present in three of the four groups, was also direct, for example, 'I'm wondering how other people feel about that' (Focus Group II). Reaching for socio-emotional content, however, ranged from direct questions, for example, 'Was that a recent loss that you had?' to summary statements, for example, 'Everybody is here for that support' (Focus Group III). Sharing personal information occurred in response to participant questions or compliments; and offering praise occurred in response to participants either expressing feelings of inadequacy or requesting evaluative feedback.

\section{Conclusions and implications}

The use of choice theory and reality therapy (Glasser, 1998, 2000; Wubbolding, 2000) as a framework for constructing focus group questions, and the goodness of fit between Glasser's approach and the client-centered and strengths oriented techniques that Cohen and Garrett (1999) recommend, may have positively affected the incorporation of Cohen and Garrett's recommendations. Similarly, the cohesion of the Clubhouse community from which focus group participants came, and that they knew one another at least by sight, may have contributed to the success of Cohen and Garrett's recommendations in this context. This cohesion and familiarity may also have contributed to the overall success of the focus groups series in suggesting additional health and wellness program components for the Clubhouse, as may the Clubhouse's already established emphasis on health and wellness.

The focus group series engaged participants in a process that resulted in suggestions for additional health and wellness components at a Clubhouse which already had implemented nutrition and exercise opportunities for its members. The suggestions emphasized mental stimulation and education, and included the Clubhouse making available puzzles and reading material at break-times and for check- 
out by members, so that materials could be taken home. Another suggestion was to offer adult basic education and tutoring of various types at the Clubhouse, so that members could improve their reading comprehension, math skills, and/or computer skills. These and other suggestions were subsequently followed up by the program developer assigned to the Clubhouse. Health and wellness program development outcomes for the pilot Clubhouse site were positive (Casstevens, forthcoming), however, long-term outcomes on the health and wellness development components at this Clubhouse are still out-standing.

The focus group facilitator in facilitating groups at this Clubhouse program redefined the rules of focus group research very much along the lines recommended in the article by Cohen and Garrett (1999). The facilitator brought knowledge of groupwork to bear on the research, and integrated groupwork and research skills. This translated into group facilitation characterized by: being personal and responsive, being sensitive to the needs of group members, focusing on socio-emotional content, building on the relationships and commonalities among group members, empathizing, and reaching for feelings. Focus group participants in the Clubhouse Health and Wellness project responded in kind. They made a socio-emotional investment in the groups and shared their feelings and thoughts with the facilitator/researcher and other group members; group cohesion and a strong sense of connection developed. The connection among group members translated into their participation in brain-storming ideas for Clubhouse health and wellness programming. Thus, the initial research goals associated with the focus groups were achieved through group process. While the Clubhouse context may have contributed to this success, the outcome seems to support Cohen and Garrett's (1999) message that social work researchers will benefit by taking the lead in revising focus group rules to be client-centered and strengths oriented, and thereby more sensitive to the socio-emotional needs of research subjects.

\section{References}

Bauer, K. W., Yang, Y. W., and Austin, S. A. (2004) 'How can we stay healthy when you're throwing all this in front of us?' findings from focus groups and interviews in middle schools on environmental influences on nutrition and 
A group work approach to focus group research in a psychiatric clubhouse program

physical activity. Health Education and Behavior, 31, 1, 34-46

Casstevens, W.J. (2010) Using reality therapy and choice theory in health and wellness program development at psychiatric psychosocial rehabilitation agencies. International Journal of Choice Theory and Reality Therapy, 29, 2, $55-58$

Casstevens, W.J. (forthcoming) A pilot study of health and wellness program development in an International Center for Clubhouse Development (ICCD) clubhouse: procedures, implementation, and implications. Psychiatric Rehabilitation Journal

Cohen, M.B. and Garrett, K.J. (1999) Breaking the rules: a group work perspective on focus group research. British Journal of Social Work, 29, 3, 359-372

Glasser, W. (1998) Choice Theory: A new psychology of personal freedom. New York: HarperCollins

Glasser, W. (2000) Counseling with Choice Theory: The new reality therapy. New York: HarperCollins

Hutchinson, D.S., Gagne, C., Bowers, A., Russinova, Z., Skrinar, G.S., and Anthony, W. A. (2006) A framework for health promotion services for people with psychiatric disabilities. Psychiatric Rehabilitation Journal, 29, 4, 241-250

International Center for Clubhouse Development (ICCD) website, located online at www.iccd.org

Jones, A.R., Hyland, R.M., Parkinson, K.N., Adamson, A.J., and The Gateshead Millennium Study Core Team (2009) Developing a focus group approach for exploring parents' perspectives on childhood overweight. Nutrition Bulletin, 34, 214-219

Kramer, B.J. and Auer, C. (2005) Challenges to providing end-of-life care to low-income elders with advanced chronic disease: Lessons learned from a model program. The Gerontologist, 45, 5, 651-660

Loeb, S., Penrod, J., and Hupcey, J. (2006) Focus groups: tactics for success. Journal of Gerontological Nursing, 32, 3, 32-38

Napolitano, M., McCauley, L., Beltran, M. and Philips, J. (2002) The dynamic process of focus groups with migrant farmworkers: the Oregon experience. Journal of Immigrant Health, 4, 4, 177-182

Patacca, D., Rosenbloom, C.A., Kicklighter, J.R., and Ball, M. (2004) Using a focus group approach to determine older adults opinions and attitudes toward a nutrition education program. Journal of Nutrition for the Elderly, 23, 3, 55-72

Pelletier, J R., Nguyen, M. Bradley, K., Johnsen, M., and McKay, C. (2005) A study of a structured exercise program with members of an ICCD certified

Groupwork Vol. 21(1), 2011, pp.46-58 
clubhouse: Program design, benefits, and implications for feasibility. Psychiatric Rehabilitation Journal, 29, 2, 89-96

Redmond, R. and Curtis, E. (2009) Focus groups: Principles and process. Nurse Researcher, 16, 3, 57-69

Smith, S.L., Blake, K., Olson, C.R., and Tessaro, I. (2002) Community entry in conducting rural focus groups: Process, legitimacy, and lessons learned. The Journal of Rural Health, 18, 1, 118-123

Tolliver, D.E. (2001) African American female caregivers of family members living with HIV/AIDS. Families in Society: The Journal of Contemporary Human Services, 82, 2, 145-156

Wubbolding, R. E. (2000) Reality Therapy for the 21st Century. New York: Routledge

Young, D. R., Gittelsohn, J., Charleston, J., Felix-Aaron, K., and Appel, L. J., (2001) Motivations for exercise and weight loss among African-American women: focus group results and their contribution towards program development. Ethnicity and Health, 6, 3/4, 227-245 